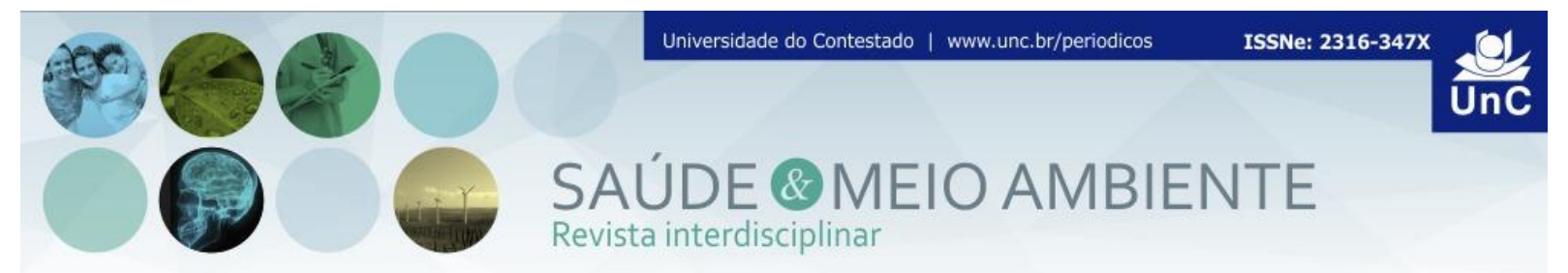

\title{
DESENVOLVIMENTO DE FORMAS FARMACÊUTICAS SEMISSÓLIDAS A PARTIR DE CAPIM-LIMÃO (CYMBOPOGON CITRATUS)
}

Letícia de Pinho da Silva ${ }^{1}$

Regina Tatiana Reck ${ }^{2}$

Francisco Noé da Fonseca ${ }^{3}$

\begin{abstract}
RESUMO
O capim-limão (Cymbopogon citratus, Poaceae) é uma planta herbácea com diversas propriedades medicinais, entre elas atividade antimicrobiana e antifúngica. Apesar do seu amplo uso etnofarmacológico, não há medicamentos fitoterápicos disponíveis, sendo sua utilização restrita a preparações caseiras (infusão). Logo, a presente pesquisa teve por objetivo avaliar estabelecer as condições de obtenção da droga vegetal e do extrato, bem como, incorpora-lo em formulações para uso tópico. A droga vegetal foi obtida em sala com desumidificação após 3 dias de armazenamento. O processo extrativo foi investigado por meio de um planejamento fatorial tendo a relação droga: solvente e concentração de etanol no solvente extrator como variáveis. Foi observado que a proporção 1:15 (droga: solvente, m/v) e etanol a $20 \%$ resultou em extratos com maior resíduo seco. Após eliminação do etanol e concentração do extrato, foram preparadas formulações semissólidas (emulsão e gel). A emulsão testada não apresentou estabilidade (separação de fase) durante o preparo, enquanto o gel resultou em uma formulação de aspecto grumoso, mas com boa espalhabilidade na pele. Assim, observa-se a potencialidade do capim-limão no desenvolvimento de formulações antissépticas de uso tópico, contudo, estudos adicionais são necessários para obtenção de uma forma farmacêutica estável, segura e eficaz.
\end{abstract}

Palavras-Chave: Cymbopogon citratus. Capim-limão. Maceração. Gel. Emulsão.

\footnotetext{
${ }^{1}$ Graduanda do Curso de Farmácia. Universidade do Contestado (UnC). Campus de Concórdia. Santa Catarina. Brasil. E-mail: leticia ps223@hotmail.com

${ }^{2}$ Graduanda do Curso de Farmácia. Universidade do Contestado (UnC). Campus de Concórdia. Santa Catarina. Brasil. E-mail: reginatatianareck@gmail.com

${ }^{3}$ Professor de Farmacognosia. Curso de Farmácia. Universidade do Contestado (UnC). Campus de Concórdia. Santa Catarina. Brasil. E-mail: fconoezin@yahoo.com.br
} 


\title{
DEVELOPMENT OF SEMISSOLID PHARMACEUTICAL FORMS FROM LEMON- GRASS (CYMBOPOGON CITRATUS)
}

\begin{abstract}
Lemon-grass (Cymbopogon citratus, Poaceae) is an herb with many medicinal properties, including antimicrobial and antifungal activity. Despite of its wide etnopharmacological use, no phytotherapic medicines are available, so that its utilization mainly as infusion. So, this research aimed to establish the conditions for obtaining the plant drug and the extract, as well as to use it as raw material for topical pharmaceutical forms. The plant drug was prepared in dehumidified room after 3 days of storage. The extraction process was investigated though a factorial plan, where the drug: solvent ratio and ethanol content in the extractor solvent were the variables. The ratio 1:15 (drug: solvent, $\mathrm{m} / \mathrm{v}$ ) and ethanol $20 \%$ resulted in the extract with highest dry residue. After ethanol elimination and the extract concentration, semisolid formulations (emulsion and gel) were prepared. The emulsion didn't present proper stability (phase separation) during the preparation; the gel led to a stable lumpy formulation, but with good skin spreadability. Based on these findings, lemon-grass shows potential for the development of topical antiseptic formulations, but additional studies are required to obtain a stable, safe and effective pharmaceutical form.
\end{abstract}

Keywords: Cymbopogon citratus. Lemon-grass. Maceration. Gel. Emulsion.

\section{INTRODUÇÃO}

O Cymbopogon citratus é conhecido popularmente pelos nomes erva-cidreira, capim-limão, capim-cidreira entre outros. E uma espécie herbácea pertencente à família Poaceae, com longas folhas aromáticas, estreitas, agudas e ásperas, com nervura central proeminente, sendo originária da Índia e encontrada difundida em vários países, e aclimatada nas regiões tropicais do Brasil (SANTOS et al., 2009). Seu uso é largamente difundido de norte a sul do país na forma de um chá de aroma e sabor agradáveis e de ação calmante e espasmolítica suaves; contêm um pouco menos que $0.5 \%$ de óleo essencial, que tem atividade antimicrobiana e é formado principalmente por citral, ao qual se atribui a atividade calmante e espasmolítica, contém também um pouco de mirceno, princípio ativo de ação analgésica. (LORENZI; MATOS, 2002).

Do ponto de vista etnofarmacológico, o capim-limão tem sido empregado como carminativo, sedativo, sudorífero, febrífugo, diurético, antipirético e antireumático. Diversos estudos têm demonstrado, além dessas atividades, outras como: calmante e espasmolítico leve, analgésico, anticarcinogênica, antibacteriana, antihelmítica, antifúngica, inseticida e larvicida, que são atribuídas aos compostos $\alpha$ citral, $\beta$-citral, e mirceno de seu óleo essencial. (LORENZI; MATOS, 2002; SOUSA et al., 1991; LEMOS et al., 2013). 
A composição deste óleo essencial é relatada em diversos trabalhos, tendo o citral e o mirceno como seus compostos majoritários. O citral é constituído pela mistura isométrica de geranial e neral, e é citado como sendo responsável pelas atividades atribuídas ao óleo, incluindo aplicação na industria farmacêutica. Outros aldeídos, como citronelal, isovaleraldído e decilaldeído, também podem ser encontrados, além de cetonas e álcoois, como geraniol, nerol, metil heptenol e farnesol (GUIMARÃES et al., 2008).

Estudos também relatam, além dos compostos citados, outros como limoneno e critronelal. É citada também a importância do citral como matéria prima de importantes compostos químicos denominados ionenos, utilizados na perfumaria e na síntese da vitamina A. Relatou-se que as atividades antimicrobianas e antifúngicas do óleo, foram atribuídas ao citral, sendo que o mirceno não apresentou atividade antimicrobiana, mas quando associado ao citral, potencializou seu efeito (SANTOS et al, 2009).

O cultivo de Cymbopogon citratus é relativamente simples, pois se trata de uma espécie muito resistente às variações de solo e clima. Santos et al. (2009) observaram que solos argilosos ou sílico-argilosos são os que oferecem melhores condições para seu desenvolvimento. As condições climáticas ideais para seu desenvolvimento são calor e clima úmido, com plena exposição solar e chuvas uniformemente distribuídas. Ainda, foi relatado pelos mesmos autores que a planta obtida nos períodos do ano com maior índice pluviométrico e temperatura resultou em maior rendimento do óleo essencial, quando comparado com as demais épocas do ano.

Essa relação também foi observada por Furlan et al. (2010), cujo estudo mostrou que o teor de óleo essencial do Cymbopogon citratus, coletado em diferentes regiões do estado de São Paulo, também foi maior nas áreas com maior índice pluviométrico mensal. Além disso, foi verificado que o teor de citral foi maior no período de baixa incidência solar (18h30 - 21h30).

Guimarães et al. (2008) realizaram um estudo sobre a oxidação do óleo essencial de capim-limão e constataram que os fatores luz e tempo tem efeito significativo sobre a estabilidade do óleo, em relação aos marcadores citral e mirceno. A degradação destes ocorreu ao longo do tempo e foi potencializada na presença de luz. Por outro lado, a temperatura favoreceu a degradação apenas do mirceno, não tendo efeito sobre o citral.

O potencial antimicrobiano do capim-limão tem sido alvo de investigação em virtude da composição do seu óleo essencial. Santos et al.(2009) relataram que o óleo essencial de Cymbopogon citratus apresentou alta inibição para as bactérias $S$. aureus $(0,08 \mathrm{mg} / \mathrm{mL})$, e baixa atividade antimicrobiana para Pseudomonas aeruginosa e E. coli $(1,25$ e $0,63 \mathrm{mg} / \mathrm{mL}$, respectivamente). Contudo, o óleo essencial obtido do capim-limão cultivado consorciado com a planta mil-folhas (Achillea millefolium L.) apresentou baixa atividade para $S$. aureus e $P$. aeruginosa $(0,63$ e $2,05 \mathrm{mg} / \mathrm{mL}$, respectivamente), enquanto para $E$. coli apresentou atividade moderada $(0,32 \mathrm{mg} / \mathrm{mL})$. 
Na última década, houve um aumento preocupante de bactérias resistentes, não apenas as bactérias de ambientes hospitalares, mas também as adquiridas na comunidade. Podemos citar como causas o uso excessivo de antibióticos, seu amplo uso veterinário, etc. Podemos incluir também os aspectos ambientais e sociais, como aglomeração de indivíduos e más condições sanitárias (REESE; BETTS; GUMUSTOP, 2002). Logo, a busca por novas substâncias antimicrobianas a partir de fontes naturais, incluindo plantas, tem ganhando ênfase. $O$ uso de plantas como fonte de medicamentos é predominante em países em desenvolvimento como uma solução alternativa para problemas de saúde (DUARTE, 2006).

Nesse contexto, considerando os efeitos antimicrobianos relatados para o óleo essencial de capim-limão e a possibilidade de utilizar essa planta como matériaprima para medicamentos fitoterápicos, o presente trabalho objetivou a padronização da obtenção da droga vegetal de capim-limão, da sua solução extrativa e a sua incorporação em formulações semissólidas com potencial uso antimicrobiano tópico.

\section{MATERIAIS E MÉTODOS}

\subsection{PREPARAÇÃO E CARACTERIZAÇÃO DA DROGA VEGETAL}

A parte aérea de capim-limão foi coletada no município de Concórdia no período da manhã. Procedeu-se a secagem da planta em sala com desumidificação. A obtenção da droga vegetal foi monitorada em função do teor de umidade, sendo considerada finalizada a secagem quando a umidade do material vegetal atingiu os limites estabelecidos pela Farmacopeia Brasileira V (8-12\%) (BRASIL, 2010).

Para determinar o teor de umidade, foi pesado aproximadamente $2 \mathrm{~g}$ das folhas em um cadinho de porcelana, tanto da planta in natura quanto ao longo do período de secagem, e foi mantida em estufa a $105^{\circ} \mathrm{C}$ por 5 horas. Após esse tempo, o cadinho foi resfriado em dessecador e a perda por dessecação foi determinada (Equação 1):

$$
\text { T.U.\%" }=100-(\mathrm{mf} / \mathrm{mi})
$$
estufa.

Onde mi é a massa de folha inicial e mf é a massa após a secagem em

No sentido de verificar a presença de contaminantes terrestres, foi determinado o teor de cinzas totais. Para isso, aproximadamente $2 \mathrm{~g}$ de folhas de capim-limão foram pesados em um cadinho e calcinados em forno mufla a $450^{\circ} \mathrm{C}$ por 2 horas. Após resfriar em dessecador, o teor de cinzas foi calculado (Equação 2): 


$$
\text { C.T. } \%=m f / m i \times 100
$$
cinzas.

Onde mi é a massa inicial de folhas de capim-limão e mf a massa final das

\subsection{PREPARAÇÃO DO EXTRATO DE CYMBOPOGON CITRATUS}

O processo extrativo foi avaliado através de um planejamento fatorial $2^{2} \mathrm{com}$ ponto central, sendo variado o teor de etanol da solução extrativa (20,60 e 95\%), e a relação droga: solvente $(\mathrm{m} / \mathrm{v}, 1: 5,1: 10$ e 1:15) de acordo com a Tabela 1. Os extratos foram preparados por maceração, na qual a droga vegetal foi adicionada de solvente e mantida em contato por $24 \mathrm{~h}$. Após esse período, o extrato foi filtrado e o volume final ajustado.

Tabela 1. Planejamento fatorial para avaliação do processo extrativo por maceração de Cymbopogon citratus (capim-limão)

\begin{tabular}{cc}
\hline Solução Hidroalcoólica & Droga:Solvente $(\mathrm{m} / \mathrm{v})$ \\
\hline $20 \%$ & $1: 5$ \\
$20 \%$ & $1: 15$ \\
$60 \%$ & $1: 10$ \\
$95 \%$ & $1: 5$ \\
$95 \%$ & $1: 15$ \\
\hline
\end{tabular}

Os extratos obtidos foram caracterizados quanto ao resíduo seco (R.S.\%). Este foi determinado com a adição de $1 \mathrm{~mL}$ de extrato em uma capsula de porcelana, a qual foi mantida em estufa a $105^{\circ} \mathrm{C}$ por 5 horas; em seguida o cadinho foi resfriado em dessecador e pesado, sendo, então, calculado o valor de resíduo (Equação 3):

$$
\text { R.S. } \%=m r s / \text { ve } \times 100
$$

Onde ve é o volume de extrato medido e mrs a massa do resíduo seco.

As interações entre as variáveis estudadas foram analisadas através de análise da variância (ANOVA) com auxílio do software Minitab 17.0 (Minitab Inc., EUA), sendo consideradas significativas quando $p<0,05$. 


\subsection{DESENVOLVIMENTO DAS FORMULAÇÕES SEMISSÓLIDAS DE CYMBOPOGON CITRATUS}

A partir dos resultados da caracterização dos extratos preparados, foi selecionada a condição extrativa que resultasse em maior resíduo seco para prosseguimento da pesquisa. Neste caso, foi preparado um extrato com a proporção droga: solvente $1: 15$ e solução hidroalcóolica $20 \%$ por maceração. A seguir, foi feita a redução do volume em estufa $50^{\circ} \mathrm{C}$ para remoção do etanol e concentração do extrato, a qual demorou 10 dias. Ao final do processo, o extrato foi caracterizado $(\mathrm{pH}$ e resíduo seco) conforme descrito anteriormente.

A fórmula utilizada para a preparação da emulsão consta na tabela 2:

Tabela 2. Composição da emulsão de Cymbopogon citratus (capim-limão)

\begin{tabular}{|c|c|c|}
\hline Fase & Componente & Quantidade (m/m) \\
\hline \multirow{4}{*}{ Fase Oleosa } & Cera Polawax & $1 \%$ \\
\hline & Vaselina líquida & $5 \%$ \\
\hline & Emulgin B2 & $1 \%$ \\
\hline & BHT & $0,05 \%$ \\
\hline \multirow{5}{*}{ Fase Aquosa } & EDTA & $0,1 \%$ \\
\hline & Nipagin & $0,15 \%$ \\
\hline & Nipazol & $0,02 \%$ \\
\hline & Propilenoglicol & $3 \%$ \\
\hline & Extrato & q.s.p $79 \mathrm{~mL}$ \\
\hline
\end{tabular}

Inicialmente, os componentes da fase oleosa foram pesados em um béquer e aquecidos em banho aquecido $\left(75^{\circ} \mathrm{C}\right)$ até dissolução dos componentes. Em outro béquer, foram pesados e dissolvidos os componentes da fase aquosa, a qual também foi aquecida no banho $\left(75^{\circ} \mathrm{C}\right)$. Por fim, a fase oleosa foi vertida sob agitação mecânica na fase aquosa, a qual foi mantida até o sistema atingir temperatura ambiente.

A outra formulação semissólida consistiu de um hidrogel (Tabela 3):

Tabela 3. Composição da emulsão de Cymbopogon citratus (capim-limão)

\begin{tabular}{lcc}
\hline & Componente & Quantidade \\
\hline Carbopol & $1 \%$ \\
Nipagin & $0,12 \%$ \\
Nipazol & $0,02 \%$ \\
Propilenoglicol & $1 \%$ \\
Trietanolamina & $1 \%$ \\
Extrato & q.s.p $100 \mathrm{~mL}$ \\
\hline
\end{tabular}

Para a preparação do gel, o extrato foi adicionado em um gral, seguida da adição do carbopol. Após $30 \mathrm{~min}$, o sistema foi homogeneizado com pistilo até dissolução completa do pó. Em seguida, os demais componentes foram adicionados e incorporados com o pistilo. Ambas as formulações foram avaliadas quanto à estabilidade e aspecto visual após o preparo. 


\section{RESULTADOS E DISCUSSÕES}

A fitoterapia constitui uma forma de terapia medicinal que vem crescendo notavelmente nestes últimos anos, de acordo com Yunes et al. (2001), esperava-se que o Brasil fosse um país privilegiado, considerando sua extensa e diversificada flora. Ainda, um grande número de grupos de pesquisa que tem contribuído significativamente para o desenvolvimento da química de produtos naturais de plantas, a quimiotaxonomia, a farmacologia de produtos naturais, e até mesmo a cosmetologia, dentre outras áreas relacionadas.

Entre as plantas medicinais com potencial antimicrobiano, tem-se o capimlimão, o qual é largamente difundido ao longo do país na forma de infusão com ação calmante e espasmolítica suaves. A planta possui em torno de $0.5 \%$ de óleo essencial, com efeito antimicrobiano, e constituído majoritariamente por citral, responsável pelo efeito calmante e espasmolítico, e mirceno, relacionado à ação analgésica (LORENZI; MATOS 2002).

Apesar do seu amplo uso etnofarmacológico, as preparações fitoterápicas derivadas de $\mathrm{C}$. citratus consistem essencialmente da infusão. No presente trabalho buscou-se desenvolver um extrato de capim-limão e usa-lo como matéria-prima para elaboração de formulações farmacêuticas. Conforme a Tabela 4, a planta in natura apresentou teor de umidade de 75,0\% $\pm 0,6$. Após 3 dias de secagem em sala com desumificação, a droga vegetal apresentou umidade de $12,7 \% \pm 0,2$, estando dentro da faixa estabelecida pela Farmacopeia Brasileira (8-12\%), a qual reduz o crescimento microbiano e aumenta a estabilidade dos componentes da droga. $O$ teor de cinzas totais da droga vegetal foi de $11,1 \% \pm 0,3$, estando próximo a valores descritos na literatura (MELO et al., 2007).

Tabela 4. Parâmetros farmacognósticos do Cymbopogoncitratus (capim-limão)

\begin{tabular}{lc}
\hline \multicolumn{1}{c}{ Parâmetro } & Valor \\
\hline Umidade da planta in natura & $75,0 \% \pm 0,6$ \\
Umidade da droga-vegetal & $12,7 \% \pm 0,2$ \\
Cinzas totais da droga-vegetal & $11,1 \% \pm 0,3$ \\
\hline
\end{tabular}

Os resultados representam média \pm desvio padrão de 3 repetições.

No sentido de otimizar o processo extrativo do capim-limão, foi utilizado um planejamento fatorial, no qual foi variado o teor de etanol do solvente extrato bem como a proporção droga:solvente. Foi verificado que o teor de etanol influenciou o resíduo seco dos extratos (ANOVA, $\mathrm{p}<0,05$ ), sendo que quanto maior o teor de etanol, menor o resíduo seco (Figura 1). Esta variação pode ser justificada pelo perfil de compostos extraídos pelos solventes, pois quanto maior o teor de água, maior a extração de açucares e outros compostos hidrofílicos; por outro lado, o etanol é mais seletivo na extração, a qual contempla as moléculas de polaridade inferior, podendo observar coloração diferenciada para cada concentração de etanol (Figura 2). No extrato preparado com etanol $20 \%$, foi obtida uma coloração mais clara em relação 
ao de etanol $60 \%$, enquanto que o extrato a $95 \%$ de etanol apresentou uma coloração esverdeada. A cor verde pode estar relacionada com a clorofila, que durante o processo de extração pode ter sido extraída juntamente com os demais componentes do capim-limão. Além disso, a relação droga: solvente também afetou significativamente o resíduo seco dos extratos (ANOVA, $p<0,05$ ) (Figura 1). Isso pode ser explicado pelo o fato de que na menor relação (1:5), a quantidade de solvente utilizada não foi capaz de extrair todo o conteúdo da droga, enquanto na maior proporção (1:15) houve a diluição do extrato pelo excesso de solvente, sendo então a proporção 1:10 intermediária na capacidade extrativa e na relação de diluição dos componentes.

Figura 1. Superfície de resposta do processo extrativo por maceração de Cymbopogon citratus (capim-limão).

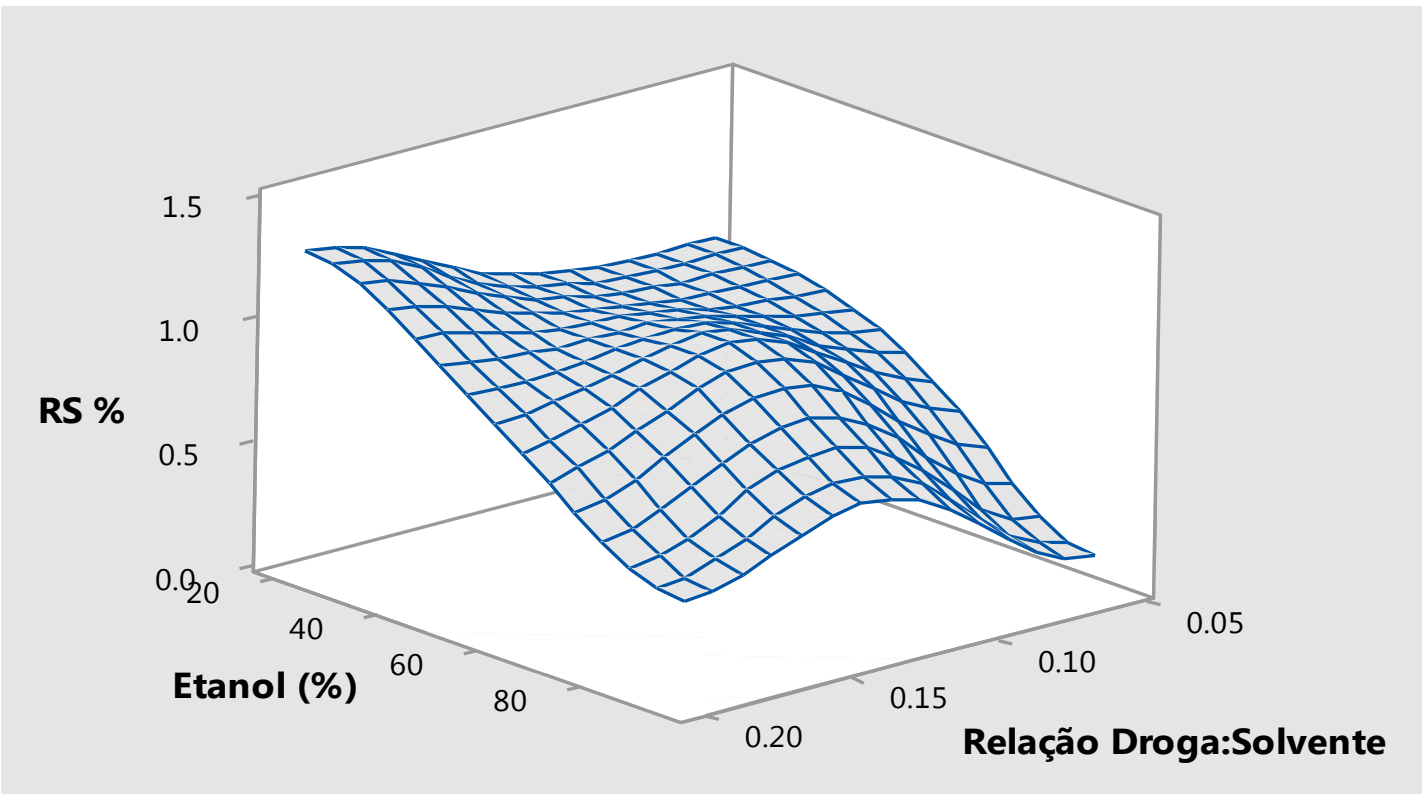

Figura 2. Aspecto visual dos extratos de Cympobogon citratus (capim-limão) em função do teor de etanol do solvente extrator.

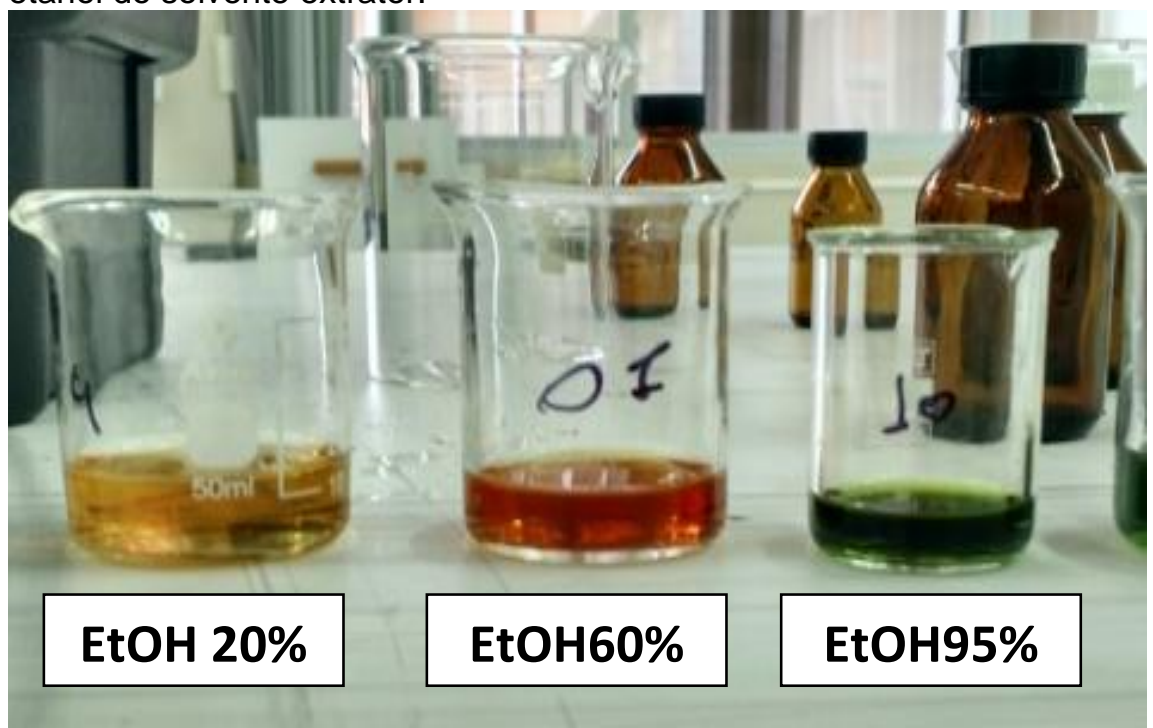

Saúde Meio Ambient. v. 5, n. 2, p. 82-92, jul./dez. 2016 
A partir do estudo da extração do capim-limão, um novo lote de extrato foi preparado utilizando a condição que resultava em maior resíduo sólido (droga: solvente 1:15 e etanol $20 \%$ ), visto que isso significa um teor maior de substâncias foi extraído da planta. Em seguida, foi realizada a concentração a $50 \%$ do volume inicial do extrato para eliminar o etanol e aumentar o resíduo solido. A Tabela 5 apresenta as variações de parâmetros físico-químicos dos extratos antes e após concentração.

Tabela 5. Caracterização dos extratos de Cymbopogon citratus (capim-limão).

\begin{tabular}{lcc}
\hline & Parâmetro & Resíduo Seco (\%) \\
\hline Extrato inicial & $1,09 \pm 0,12$ \\
Extrato concentrado & $1,45 \pm 0,04$ \\
\hline
\end{tabular}

Os resultados representam média \pm desvio padrão de 3 repetições.

Além do aumento do resíduo seco, outro parâmetro que também variou com a etapa de concentração foi o $\mathrm{pH}$, o qual diminui de 5,7 para 4,7. Isso pode ser justificado pela redução de volume do extrato, o que aumentou a concentração dos compostos de caráter ácido do fitocomplexo extraído, o que reduziu o valor de $\mathrm{pH}$.

No sentido de desenvolver formulações fitoterápicas de uso tópico de capimlimão, foram preparadas duas formulações semissólidas (emulsão e gel). A incorporação do extrato na fase aquosa da emulsão desestabilizou o sistema, que pode ser confirmado pela separação de fase logo após o término da agitação. Novo teste foi realizado incorporando mais $1 \%$ de tensoativo, mas não foi suficiente para emulsificar. Neste caso, possivelmente, a variedade de compostos presentes no extrato alteraram a tonicidade da fase aquosa, o que pode ter diminuindo o poder estabilizante dos tensoativos utilizados, sendo necessários estudos adicionais para escolher um sistema tensoativo mais adequado para o extrato desenvolvido. Por outro lado, para a formulação de gel foi possível obter um sistema estável. Contudo, foi necessário adicionar mais $1 \%$ de carbopol à formulação para garantir a geleificação do sistema. Apesar do aspecto visual do gel produzido ser grumoso, ele apresentou boa espalhabilidade na pele. Ainda assim, estudos adicionais de formulação precisam ser realizados para melhorar a consistência do produto.

\section{CONCLUSÕES}

A partir dos resultados obtidos, a droga vegetal de capim-limão pode ser obtida em sala com desumidificação após três dias e a melhor condição de extração da droga por maceração é droga: solvente 1:15 e solvente extrator constituído por etanol $20 \%$. Do ponto de vista farmacotécnico, para as formulações testadas o extrato de capim-limão foi adequado apenas para a preparação de gel, indicando a potencialidade dos derivados da planta para elaboração de produtos fitoterápicos para uso tópico com finalidade antisséptica. Ainda assim, estudos complementares 
são necessários para a obtenção de uma formulação inovadora de C. citratus, que apresente qualidade, efetividade e segurança ao paciente.

\section{REFERÊNCIAS}

BRASIL. Farmacopéia Brasileira. 5.ed. Brasília: Agência Nacional de Vigilância Sanitária, 2010. v. 1.

DOS SANTOS, A. C. A. et al. Efeito fungicida dos óleos essenciais de Schinus molle L. e Schinus terebinthifolius Raddi, Anacardiaceae, do Rio Grande do Sul. Revista Brasileira de Farmacognosia, v. 20, n. 2, p. 154-159, 2010.

DUARTE, M. C. T; Atividade antimicrobiana de plantas medicinais e aromáticas utilizadas no Brasil. Multi Ciência. Disponível em: <https://www.multiciencia.unicamp.br/artigos_07/a_05_7.pdf> Acesso em: $01 \mathrm{dez}$. 2015.

FURLAN, M. R. et al. Variação dos teores de constituintes voláteis de Cymbopogon citratus (DC) Staf, Poaceae, coletados em diferentes regiões do Estado de São Paulo. Revista Brasileira de Farmacognosia, v., 20, n. 5, p. 686-691, 2010.

GUIMARÃES, L. G DE L; CARDOSO, M. G; ZACARONI, L. M; ET AL. Influência da luz e da temperatura sobre a oxidação do óleo essencial de capim limão (Cymbopogon citratus (D.C.) Stapf). Química Nova, v. 31, n. 6, p. 1476-1480, 2008.

LEMOS, G.C.S; SANTOS, A.D; FREITAS S.P; ET AL; Controle de plantas invasoras em cultivo orgânico e convencional de capim-limão (Cymbopogoncitratus). Revista Brasileira PI. Med., v. 15, n. 3, p. 405-414, 2013.

LORENZI, H; MATOS, F. J. A.; Plantas medicinais no Brasil, nativas e exóticas. São Paulo: Instituto plantarum de estudos da flora LTDA, 2002.

MELO, J. G. et al. Qualidade de produtos a base de plantas medicinais comercializados no Brasil: castanha-da-índia (Aesculus hippocastanum L.), capimlimão (Cymbopogon citratus (DC.) Stapf) e centela (Centella asiática (L.) Urban). Acta. Bot. Bras. v. 21, n. 1, p. 27-36, 2007.

MICHELIN, D.C. et al. Avaliação da atividade antimicrobiana de extratos vegetais. Revista Brasileira de Farmacognosia, v. 15, n. 4, p. 316-320, 2005.

NASCIMENTO, P. F. C. et al. Atividade antimicrobiana dos óleos essenciais: uma abordagem multifatorial dos métodos. Revista Brasileira de Farmacognosia, v. 17, n. 1, p. 108-113, 2007. 
OLIVEIRA, M. M. M. et al. Rendimento, composição química e atividade antilisterial de óleos essenciais de espécies de Cymbopogon. Revista Brasileira PI. Med. v. 13, n. 1, p. 08-16, 2011.

REESE, R. E; BETTS, R. F; GUMUSTOP, B. Manual de Antibióticos. Rio de Janeiro: Guanabara Koogan, 2002.

SANTOS, A. et al. Determinação do rendimento e atividade antimicrobiana do óleo essencial de Cymbopogon citrarus (DC.) Stapf em função de sazonalidade e consorciamento. Revista Brasileira de Farmacognosia. v. 19, n. 2, p. 436-441, 2009.

SARTORATTO, A. et al. Composition and antimicrobial activity of essential oils from aromatic plants used in Brazil. Brazilian Journal of Microbiology, v. 35, p. 275-390, 2004.

SCHERER, R. et al. Composição e atividades antioxidantes e antimicrobiana dos óleos essenciais de cravo-da-índia, citronela e palmarosa. Revista Brasileira de Plantas Medicinais, v., 11, n. 4, p. 442-449, 2009.

YUNES, R.A; PEDROSA, R. C; FILHO, V.C; Fármacos e fitoterápicos: A necessidade do desenvolvimento da indústria de fitoterápicos e fitofármacos no Brasil. Química Nova. v. 24. n. 1, p. 147-152, 2001.

AGRADECIMENTO: Agradecemos à Coordenação dos Laboratórios de Ciência e Tecnologia da UnC pelo acesso aos laboratórios necessários para a execução de atividades. O presente trabalho foi realizado com apoio da Universidade do Contestado - Fundo de Apoio a Pesquisa (FAP-UnC).

Artigo recebido em: 15/12/2015

Artigo aprovado em: 12/11/2016 